Orissa Journal of Commerce

Vol. 42, Issue 3, July-September 2021

ISSN: 0974-8482

(C) OJC India. All Right Reserved

URL: www.ojcoca.org

DOI: https://doi.org/10.54063/ojc.2021.v42i03.08

\title{
Linking Transformational Leadership with Employee Engagement through Organizational Commitment and Organizational Culture
}

\author{
Vijaya Lakshmi Rakatu ${ }^{1 *}$, Ashok Kumar Chandra ${ }^{2}$ and Mahesh Kumar Soma ${ }^{3}$ \\ ${ }^{1}$ Research Scholar, Chbattisgarb Swami Vivekanand Technical University, Bhilai, Chbattisgarb.E-mail: vijayarakatu@yahoo.com \\ ${ }^{2}$ Associate Professor, Bhilai Institute of Technology, Bhilai, Chbattisgarh.E-mail: ash_chandra@rediffmail.com \\ ${ }^{3}$ Associate Professor, IBS Hyderabad, IFHE University, Hyderabad, Telangana. E-mail: maheshk@ibsindia.org \\ ${ }^{*}$ Corresponding Author
}

To cite this paper

Rakatu, V.L., Chandra, A.K., \& Soma, M. K. (2021). Linking

Transformational Leadership with Employee Engagement through

Organizational Commitment and Organizational Culture. Orissa

Journal of Commerce. 42(3), 96-108.

Keywords

Employee engagement, Job satisfaction, Organizational commitment, Organizational culture, Transformational leadership

JEL Classification J28, J62, M14, D23, D73

\begin{abstract}
This paper intends to understand the employee engagement methods within the organization through the presence of organizational culture and each competency of an improved organizational commitment. Data have been analyzed using smart PLS-SEM software program for a sample of 412 bank employees from public and private sector banks in Chhattisgarh, India. The tools of analysis such as mean, standard deviation, tabulations, have used. Correlations, bootstrapping, discriminant validity, goodness of fit, reliability, standardized root mean square residual are performed to test the hypotheses. Checking for the presence of bias, a confirmatory factor-analytic approach is used in the research for the Harman one factor trial. The findings reveal that transformational leadership is one of the important internal changes through resources, time allocation and organizational commitment enables the high level of employee engagement within a culture and commitment, which shows an impact on the employee job satisfaction.
\end{abstract}

\section{Introduction}

Employee engagement movement was pioneered by Kahn (1992). It is a constructive insistence in which an employee goes above and beyond his assigned responsibilities to disclose a higher degree of ownership and to support the financial interests of the organization in all-inclusive manner (Robinson et al., 2004). The three extraordinary dimensions of commitments are verified with the useful resource of the usage of employees at specific levels of organization and may be unbiased of each other (Allen et al., 1996). For the betterment of organization, engagement is a form of off characteristic or average overall performance of a person that cherishes (Macey et al., 2008). According to Buchingham and Coffman (1999), organizational engagement and work honestly have an impact on commitment, employee absenteeism, morale and productivity with inside the organization. Many researchers have shown the presence of an innovative relationship among commitment and engagement with productivity, profitability. 
Linking Transformational Leadership with Employee Engagement through Organizational Commitment...

Christain et al. (2011) shown that leadership is an important element that accords the work environment and the behavior of employees realizes their work. Precisely, transformational leadership trait collectively with intellectual stimulation and person aid also can moreover make a supportive organizational circumstance that effect excessive duration of work engagement (Avolio and Bass, 1995).

Employee engagement has been researched with the aid of using professional and academic system and is advised because the facts which regulate the relation of the employee with the highest level of engagement and overall results on the job (Sundry, 2011). Some research in developing and increasing economies formalize that there is a positive association between employee engagement and emotional commitment, however only a few have advised on engagement's effect on length and dedication. In-spite of accessibility an amount of research on employee engagement and it's have an effect on company there's an informative expertise gap with-inside the literature, which continuously affect the need for added primary exploration on this object within various ascertain and various demographic sections.

\section{Review of Literature}

Generally, transformational leadership activity including reflective stimulation and individual work may also cause a climate of the organization that impact excessive stages of work engagement (Salanova, 2011; Avolio and Bass, 1995). Furthermore, transformational leaders who set new goals, reward workers for good results, and are engaged with employees might play a role in delivering psychological safety and emotions of connection to one's employment (Macey, 2008; Kahn 1990).

The introduction of authorized systems at job, however the opinions of transformational leadership revolved into develop through Burns (1978) in his studies, similarly progressive through Bass (1999). According to Bass (1985), transformational leadership fosters corporate culture and creativity, and this style of leader expresses a specific vision, cultivates supporters, and fosters trait growth.

Transformational leaders influence their followers, encouraging them to look beyond their personal ambitions by focusing on the organization's goals, and persuading them to adopt a unique perspective (Avolio et al., 1995). Organizational culture has become the topic of research in recent years, as a result of differences in the values and standards of employees from various cultures. It has been determined that these differences are likely to resurface sooner or later in global business practices and working environments, because of inability to recognize unique people's thoughts and attitudes and adapt to overseas strategies (Black et al., 1992, Tarique, et al., 2016).

According to Allen and Meyer (1990) organizational commitment is the belief and response of the statements and concept of the organization they consist with the good with the aid of using the employee to be related to that organization. Employee commitment in an organization is sorted into three stages, affective, normative and continuation commitment. Affective commitment is concerned with people emotional attachment to the company, whereas continuation commitment is concerned with expenditures associated to time away from the organization, and normative commitment is concerned with the organization's ethical commitment. Commitment is a strong accepts as true with and adoption of the organization's values and antecedent. A dedicated employee will put a huge amount 
of effort on behalf of a company and a powerful aspiration to support organization membership (Mowday et al., 1982). According to Gruenfeld et al. (1996) data diversity has noted the employee's behaviour of their workplace is motivated with three unique cultures: national, activity and their culture of the organization. Generally, a person's attitudes and values about his or her profession are mainly divine with the gift of using their personal belief and ideals, that have been realized in the exposure of family for the period of his/her in advance development.

In 2009, Tharp shown in his research employees had been assumed into consideration to be greater conscious of the social power of peer business organization rather than a trainer's incentives and management. Many people were motivated to work regardless of whether or not the employees, organizational approaches, formulation, and behavioural principles dictated their overall success and the institution's failure (Tharp, 2009). Chalofsky and Krishna (2009) in their paper found that organizational commitment and employee engagement are developed as a colourful concept. Because of their optimistic relationships with employees' behaviours, which advise organizational overall execution and profit-making.

Rigorous research on organizational commitment have shown that there exists a effective relationship among affective commitment and employee engagement, however only a some researchers present has targeting engagement's effect on the alternative element of commitment generally normative and continuance commitment. According to Demerouti et al. (2001) consequence of engagement on organizational commitment with the assistance of using Schaufeli et al. (2007) found out that there exists a positive association among engagement and organizational dedication, the fact that growth engagement level additionally raises performance, satisfaction, improves group action and exposes an extra process of motivation and innovation. Learning and motivation had been additionally stimulated by better engagement level of employees (Schaufeli et al., 2007).

Brown and Leigh (1996) exposed that value of engagement into the work and additionally improve the commitment of time and quality into organizations work. They also discovered that the psychological atmosphere has a strong relationship with emotional and cognitive satisfaction, engagement, and motivation. Now, additionally to return a look at the mediating result of engagement at the association among commitment of the organization and job resources, it became dependent that engagement and being performed a most important mediating function of their several anticipated model (Bakker et al., 2008).

Spector (1997) found that job satisfaction is combined of the most on a regular basis observed components in culture of the organization, behaviour and various occupational phenomena from job design to supervision. Job satisfaction is a general term that refers to an employee's feelings towards his or her job. Sowmya and Panchanatham (2011) research has discovered that job satisfaction has multi-dimensional phenomenon, pleased through numerous external and internal elements, which includes individual values, attitudes, expectations, personality and the job's nature, the possibility provided etc. Herzberg (1974) examined that the motivation-hygiene model is used to provide the foundation for job satisfaction research and evaluation. Factors, motivators, and hygiene problems are said to be causing workers' negative feelings about their employment.

Herzberg (1974) developed the motivation-hygiene theory, in conformation with which job satisfaction and dissatisfaction are separated and from time to time ever unrelated, phenomena, which 
Linking Transformational Leadership with Employee Engagement through Organizational Commitment...

they have to not be calculated at the equal continuum. Worker emotions towards their job are troubled from issues, motivators and hygiene issues. Intrinsic component-motivators are assumed into circumstance to be fulfilled, even as extrinsic factors - hygiene factors are sensed as dissatisfies. Hygiene factors consist of personal working environment, supervision, job security, HR policies and administration. To analyse the employee's usual mind-set towards their work, at the same time as the prospect approach is used with inside the work of distinct job elements which might be potentially to encourage or save you job satisfaction and dissatisfaction given by Sowmya and Panchanatham (2011). Leadership is an essential factor that affects the work environment and how employees behave when they believe in their work (Christian et al., 2011).

\section{Objectives and Hypotheses of the Study}

\subsection{Objectives of the Study}

The main objectives of this study are:

- To find the transformational leadership has a favorable relationship with organization commitment and organizational culture.

- To examine how employee engagement improve the conditions at selected Public and Private Sector Banks in selective cities of Chhattisgarh.

\subsection{Hypotheses of the Study}

In order to achieve these objectives, the following hypotheses are developed:

$\mathrm{H}_{01}$ : Transformational leadership has a favorable relationship with organizational commitment, and organizational culture at selected Public and Private Sector Banks in Chhattisgarh.

$\mathrm{H}_{02}$ : Organizational commitment positively mediates the influence of organizational culture on employee engagement at selected Public and Private Sector Banks in Chhattisgarh.

$\mathrm{H}_{03}$ : The existence of employee engagement will find out the extent to which the employee achieves enhanced job satisfaction at selected Public and Private Sector Banks in Chhattisgarh.

\section{Methodology}

The respondents of this investigation were 412 bank employees at the selected areas of Chhattisgarh.18 banks were randomly selected, out of which 11 are public sector banks and 7 are private sector banks. Pilot study was conducted prior, 450 questionnaires were distributed and 423 were received but according to Hair et al. (2010) questionnaires with missing values more than $10 \%$ should not be considered for analysis. So, 412 are valid responses and 11 are invalid responses were received from all banks and response rate was $92 \%$ (valid responses). Out of which 173 were from junior level, 145 from middle level and the remaining 94 from senior level. Out of 412 respondents, 169 are female respondents which is $41.02 \%$ and 243 are male respondents that is $58.99 \%$. This indicated that out of the total respondents surveyed, below 25 years of age group are 33.01\%, 26-40 years age group are $44.66 \%, 41$ years and above age group are $22.33 \%$. Most of the communicator has been employed in the system

Orissa Journal of Commerce, 42(3) (C) 2021 
for more than 5 years. Which is evidenced that work experience of 5 years and above is $39.81 \%$ ? Moreover, work experience of less than one year is $7.77 \%, 1-2$ years is $22.57 \%$ and $2-5$ years is $29.85 \%$.

(a) Transformational leadership was analyzed by using seven items scale of Bass (1985). This communicates a vision, trains employees, gives assistance, empowers employees, is creative, inspiring, and is engaging.

(b) Organizational culture has been analyzed by using five items scale of Saks (2006).

(c) Organizational commitment has been measured with six items scale of Saks (2006).

(d) Employee Engagement Scale (EES) has been measured by using six items scale of McCollKennedy (2002).

(e) Job satisfaction has been analyzed by using seven items scale of Saks (2006).

\section{Data Analysis and Results}

As a method of checking for the presence of bias, a confirmatory factor-analytic approach was used in the research for the Harman one factor trial (Podsakoff et al., 2003). A greater regrettable match for the one-factor type might impart that simple technique replacement would not establish are liable risk.

Satorra-Bentler will be the consequence of this model $\chi_{(188)}^{2}=586.44 ; \frac{\chi_{(188)}^{2}}{188}=3.11$.

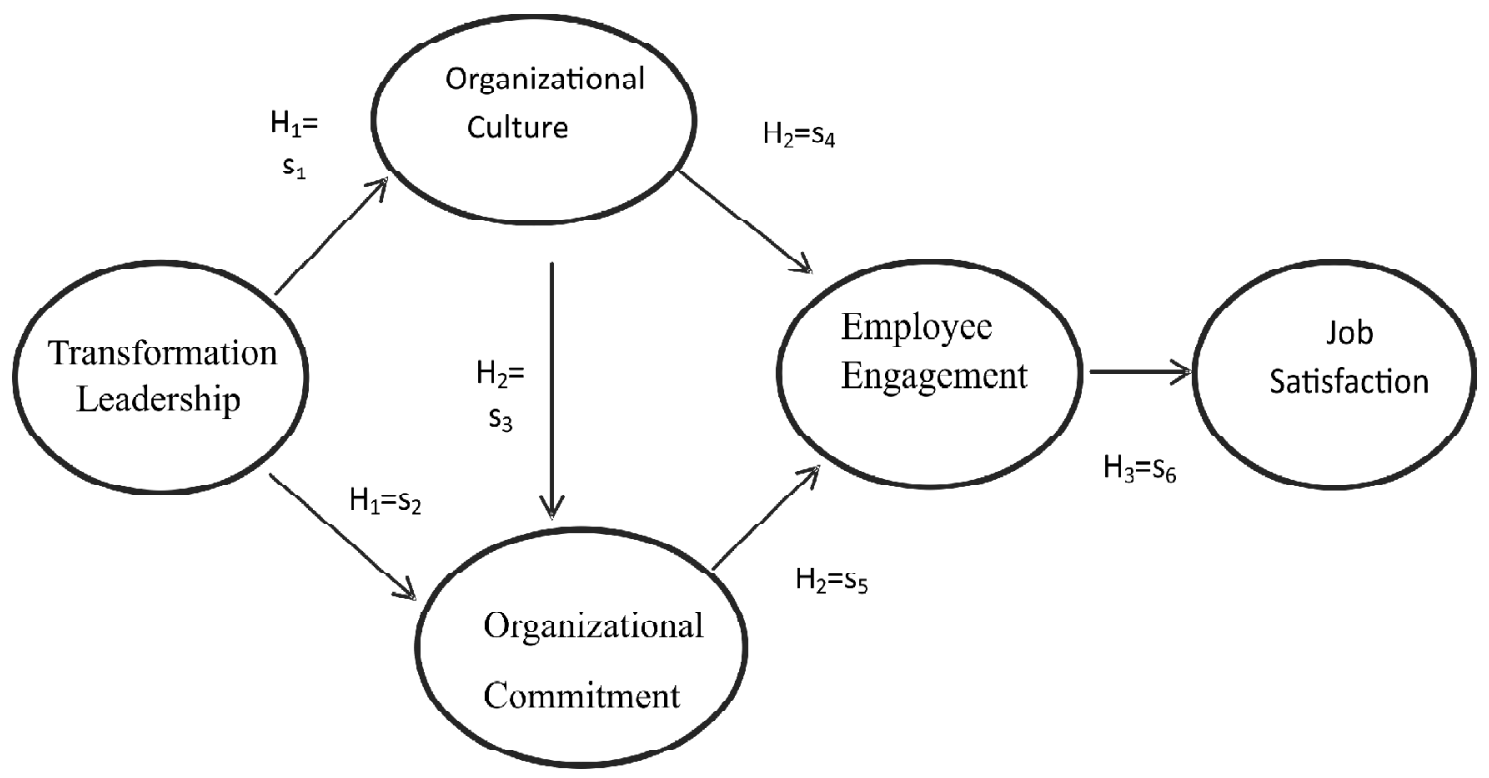

Figure 1: Proposed Theoretical Model

Source: Authors' own compilation 
Linking Transformational Leadership with Employee Engagement through Organizational Commitment...

The data was analysed and the model was tested using PLS-SEM (Figure 1) which is recommended by Massaro et al. (2015). Transformational leadership style, Organizational culture, Organizational commitment, Employee engagement and Job satisfaction have been a specific as smart PLS Mode. As a preliminary measure, an appraisal of the orbicular version fit changed into needful.

Table 1 demonstrates that the theory's fit modality displays a realistic data fit. Value of the standardised root mean square residual (SRMR) is 0.055 and all inconsistencies were below $99 \%$ quantile of the bootstrap inconsistencies $\left(\mathrm{HI}_{99}\right)$, it proposes a realistic good estimation model fit by Henseler et al. (2014). Reliability of the all items will satisfy. Practically, all external loading are more than 0.7 ; a couple of factors with an excessively low external loading had been eliminated. Hence, the items are reliable. The composite reliability item received a score of 0.7 , while the average variance retrieved received a score of 0.5 , were higher than Bagozzi (1988) in terms of scale of measurement dependability for all steps (Table 3).

In table 1, according to Fornell and Larcker, (1981) the discriminant's validity was evaluated by comparing each concept that was more closely connected to its own measurements than others. Also, by Henseler et al. (2014) as all HTMT are less than 0.8 , therefore, all variables that achieve discriminant validity (Table 3).

Table 1: Scale Reliability and Confirmatory Factor Analysis, Construct Summary

\begin{tabular}{lll}
\hline Items & Loading & Reliability (AVE, SCR) \\
\hline Transformational Leadership (TL) & & \\
TL1 & 0.77 & \\
TL2 & 0.82 & AVE $=0.54$ \\
TL3 & 0.88 & SCR $=0.887$ \\
TL4 & 0.81 & \\
TL5 & 0.79 & \\
\hline Organizational Culture(OC) & & \\
OC1 & 0.72 & AVE $=0.647$ \\
OC2 & 0.86 & SCR $=0.916$ \\
OC3 & 0.83 & \\
OC4 & 0.84 & \\
OC5 & 0.87 & \\
\hline Organizational Commitment (OCOM) & & AVE $=0.629$ \\
OCOM1 & 0.78 & SCR $=0.91$ \\
OCOM2 & 0.80 & \\
OCOM3 & 0.78 & \\
OCOM4 & 0.84 & \\
OCOM5 & 0.71 & \\
OCOM6 & 0.81 &
\end{tabular}

Contd. table 1

Orissa Journal of Commerce, 42(3) (C) 2021 
Vijaya Lakshmi Rakatu, Ashok Kumar Chandra and Mahesh Kumar Soma

\begin{tabular}{lll}
\hline Employee Engagement (EEngmt) & & \\
EEngmt1 & 0.79 & \\
EEngmt2 & 0.84 & AVE $=0.719$ \\
EEngmt3 & 0.90 & SCR $=0.911$ \\
EEngmt4 & 0.82 & \\
\hline Job Satisfaction (JS) & & \\
JS1 & 0.73 & AVE $=0.58$ \\
JS2 & 0.85 & SCR $=0.90$ \\
JS3 & 0.82 & \\
JS4 & 0.84 & \\
JS5 & 0.87 & \\
JS6 & 0.65 & \\
\hline
\end{tabular}

Source: Compiled from Survey Data

Note: Scale Composite Reliability (SCR) of $p_{c}=\left(\Sigma \lambda_{i}\right)^{2} \operatorname{var}(\xi) /\left[\left(\Sigma \lambda_{i}\right)^{2} \operatorname{var}(\xi)+\Sigma \theta_{i i}\right]$ (Bagozzi and Yi, 1988). Average variance extracted (AVE) of $p_{c}=\left(\Sigma \lambda_{i}^{2} \operatorname{var}(\xi)\right) /\left[\left(\Sigma \lambda_{i}^{2} \operatorname{var}(\xi)+\Sigma \theta_{i i}\right]\right.$ (Fornell and Larcker, 1981).

Since the Q-square values are greater than zero, according to our findings model has a strong predictive relationship with job satisfaction (Q-square-0.056), employee engagement (Q-square-0.201), organizational culture (Q-square-0.073) and organizational commitment (Q-square-0.265).

Table 2: Confirmatory Composite Analysis, Goodness of Fit and Bootstrap based on 99 and 95 Percent Quantiles

\begin{tabular}{lcccccc}
\hline $\begin{array}{l}\text { Goodness } \\
\text { of Fit }\end{array}$ & $\begin{array}{c}\text { Estimated } \\
\text { Model }\end{array}$ & $H_{95}$ & $H i_{99}$ & $\begin{array}{c}\text { Maturated } \\
\text { Model }\end{array}$ & $H i_{95}$ & $H_{99}$ \\
\hline SRMR & 0.069 & 0.081 & 0.079 & 0.099 & 0.088 & 0.095 \\
$\mathrm{D}_{\text {ULS }}$ & 0.865 & 1.086 & 1.642 & 1.624 & 1.344 & 1.875 \\
$\mathrm{~d}_{\mathrm{G}}$ & 0.516 & 0.559 & 0.756 & 0.682 & 0.589 & 0.619 \\
\hline
\end{tabular}

Note: $\mathrm{D}_{\mathrm{ULS}}$ : "Unweighted Least Squares Discrepancy" and $\mathrm{d}_{\mathrm{G}}$ : "Geodesic Discrepancy".

Source: Compiled from Survey Data

Table 4 shows that using bootstrapping to test hypotheses suggests that transformation leadership is effective and positively related with both organizational culture $\left(s_{1}=0.346, \mathrm{p}<0.01\right)$, organizational commitment $\left(\mathrm{s}_{2}=0.365, \mathrm{p}<0.001\right)$. Again, positive relationships survive between organizational culture and organizational commitment $\left(\mathrm{s}_{3}=0.388, \mathrm{p}<0.01\right)$ and between organizational culture and employee engagement $\left(\mathrm{s}_{4}=0.380, \mathrm{p}<0.01\right)$. Additionally, the outcome shows that organizational commitment 
Linking Transformational Leadership with Employee Engagement through Organizational Commitment...

Table 3: Correlation Matrix

\begin{tabular}{|c|c|c|c|c|c|c|c|c|c|c|}
\hline & & \multirow[t]{2}{*}{ Mean } & \multirow[t]{2}{*}{ S.D. } & \multirow{2}{*}{$\begin{array}{c}\text { Cronbach's } \\
\text { Alpha }\end{array}$} & \multirow[t]{2}{*}{ HTMT } & \multicolumn{5}{|c|}{ Correlation matrix } \\
\hline & & & & & & 1 & 2 & 3 & 4 & 5 \\
\hline 1. & $\begin{array}{l}\text { Transformational } \\
\text { leadership }\end{array}$ & 4.199 & 1.408 & 0.839 & 0.687 & 1 & & & & \\
\hline 2. & $\begin{array}{l}\text { Organizational } \\
\text { Culture }\end{array}$ & 4.026 & 1.165 & 0.886 & 0.769 & 0.753 & 1 & & & \\
\hline 3. & $\begin{array}{l}\text { Organizational } \\
\text { Commitment }\end{array}$ & 4.162 & 1.106 & 0.879 & 0.795 & 0.777 & 0.775 & 1 & & \\
\hline 4. & $\begin{array}{l}\text { Employee } \\
\text { engagement }\end{array}$ & 4.204 & 1.001 & 0.868 & 0.752 & 0.773 & 0.761 & 0.992 & 1 & \\
\hline 5. & Job satisfaction & 4.021 & 1.121 & 0.870 & 0.734 & 0.77 & 0.952 & 0.782 & 0.756 & 1 \\
\hline
\end{tabular}

Source: Compiled from Survey Data

Table 4: Statistical Models (Direct Effects)

\begin{tabular}{lcccc}
\hline Links & \multicolumn{4}{c}{ Level of Confidence } \\
\hline $\mathrm{TL} \rightarrow \mathrm{OC}$ & Path coefficients & $t$-values & $5 \% C I_{\text {low }}$ & $95 \% C I_{\text {bigh }}$ \\
$\mathrm{TL} \rightarrow \mathrm{OCOM}$ & $\mathrm{S}_{1}=0.346$ & 4.608 & 0.333 & 0.434 \\
$\mathrm{OC} \rightarrow \mathrm{OCOM}$ & $\mathrm{S}_{2}=0.365$ & 5.124 & 0.822 & 0.474 \\
$\mathrm{OC} \rightarrow$ EEngmt & $\mathrm{S}_{3}=0.388$ & 4.208 & 0.274 & 0.496 \\
OCOM $\rightarrow$ EEngmt & $\mathrm{S}_{4}=0.380$ & 5.849 & 0.350 & 0.526 \\
EEngmt $\rightarrow$ SS & $\mathrm{S}_{5}=0.312$ & 4.787 & 0.244 & 0.443 \\
\hline
\end{tabular}

Notes: TL: Transformation leadership, OC: Organizational culture, OCOM: Organizational commitment, EE: Employee Engagement and JS: Job satisfaction.

Source: Compiled from Survey Data

had a favourable impact on employee engagement at level of $s_{5}=0.312,(p<0.01)$, and that Employee engagement at level of $\mathrm{s}_{6}=0.193,(\mathrm{p}<0.01)$ had a substantial effect on job satisfaction.

Our study furnishes a post-hoc mediate outcome analysis for externalities, which is related to the impacts of independent variables on the dependent variable via the mediator. According to Preacher et al., (2008), table 5 exhibits, because the bootstrapped interval doesn't include zero value, all indirect effects were shown to be essential. As a result, for $\mathrm{H}_{1}, \mathrm{H}_{2}$ and $\mathrm{H}_{3}$ the conclusion provided a complete determinant. 
Vijaya Lakshmi Rakatu, Ashok. Kumar Chandra and Mahesh Kumar Soma

Table 5: Indirect Effects

\begin{tabular}{lcccc}
\hline Indirect effects though & Point estimate & \multicolumn{3}{c}{ Confidence Intervals (95\%) } \\
\cline { 3 - 5 } & & $5 \% C_{\text {low }}$ & $95 \% C_{\text {bigh }}$ & Significance \\
\hline $\mathrm{OC} \rightarrow \mathrm{OCOM} \rightarrow \mathrm{EE} \rightarrow \mathrm{JS}$ & $0.160^{* * *}$ & 0.089 & 0.352 & 0.000 \\
$\mathrm{OC} \rightarrow \mathrm{OCOM} \rightarrow \mathrm{EE}$ & $0.225^{* * *}$ & 0.065 & 0.156 & 0.001 \\
$\mathrm{OC} \rightarrow \mathrm{EE} \rightarrow \mathrm{JS}$ & $0.080^{* * *}$ & 0.058 & 0.132 & 0.006 \\
$\mathrm{TL} \rightarrow \mathrm{OC} \rightarrow \mathrm{OCOM}$ & $0.213^{* * *}$ & 0.067 & 0.189 & 0.000 \\
$\mathrm{TL} \rightarrow \mathrm{OC} \rightarrow \mathrm{OCOM} \rightarrow \mathrm{EE}$ & $0.378^{* * *}$ & 0.239 & 0.484 & 0.000 \\
$\mathrm{TL} \rightarrow \mathrm{OC} \rightarrow \mathrm{OCOM} \rightarrow \mathrm{EE} \rightarrow \mathrm{JS}$ & $0.072^{* * *}$ & 0.046 & 0.126 & 0.001 \\
\hline
\end{tabular}

Notes: TL: Transformation leadership, OC: Organizational culture, OCOM: Organizational commitment, EE: Employee Engagement and JS: Job satisfaction.

Source: Compiled from Survey Data

Table 6: Indicators of Endogenous Variables are being Evaluated for their Predictive Capacity

\begin{tabular}{lcccccccc}
\hline PLS & RMSE & Q-square & $L M$ & RMSE & Q-square & PLS-LM & RMSE & Q-square \\
\hline JS1 & 1.504 & 0.027 & RND1 & 1.521 & 0.031 & RND1 & -0.017 & 0.006 \\
JS2 & 1.435 & 0.031 & RND2 & 1.445 & 0.024 & RND2 & -0.010 & 0.007 \\
JS3 & 1.391 & 0.028 & RND3 & 1.412 & 0.019 & RND3 & -0.021 & 0.009 \\
JS4 & 1.548 & 0.035 & RND4 & 1.562 & 0.026 & RND4 & -0.014 & 0.009 \\
JS5 & 1.482 & 0.040 & RND5 & 1.512 & 0.032 & RND5 & -0.020 & 0.008 \\
JS6 & 1.571 & 0.037 & RND6 & 1.582 & 0.026 & RND6 & -0.011 & 0.011 \\
JS7 & 1.412 & 0.032 & RND7 & 1.435 & 0.025 & RND7 & -0.023 & 0.007 \\
\hline
\end{tabular}

Source: Compiled from Survey Data

Predictive power in our model was calculated by using the theory of Shmueli et al. (2016, 2019). Danks et al. (2018) was used Smart-PLS version 3.2.6 in their research. Our study reveal that whether PLS-SEM residual errors are higher than linear regression residual errors (LM), indicating that the expectation has predictive power in this case as shown in table 6, because of the high arrangement spatiality of errors, all $\mathrm{Q}^{2}$ predict for all job satisfaction facts are positive, and we utilise RMSE as residual error. As can be shown, the residual errors for all seven facts are greater than linear regression residual model, implying that our model has a good predictive capacity.

\section{Discussion}

Organizational commitment of organization allows a reorientation of the effective employee engagement of management and its discrete employees in the direction of new outcomes, organizational subculture improves data associated with values, expectancies and practices that manual and articulate movements 
Linking Transformational Leadership with Employee Engagement through Organizational Commitment...

of all abilities received. In view of the individual factor, such knowledge may be associated with the satisfaction of positive system such as involving, feeling or the use of a selected technology. In the environment of an enterprise, organizational subculture connects to the individual or organisational memories. This observation has determined that now no longer simplest transformational leadership helps each organizational culture and organizational commitment. However, job satisfaction is predicated on each direct and indirect results of organizational culture and organizational commitment. Results of hypotheses confirm that transformational leadership enables to keep stability among the implementation of organisational culture and commitment to recognize destiny wishes of the customer satisfaction with inside the context of Chhattisgarh banks. Therefore, "Transformational leadership promotes organizational extrude and innovation, and this type of leader communicates a clear vision, evokes followers and creates trust" Bass, (1985).

According to Howell and Avolio (1993), Yukl, (1981) examined that subordinates generally tend to behave beyond their very own expectancies in this kind of way. Transformational leaders give confidence to their group to think beyond their individual interests by focusing on the organization's goals, and they force them to see things from different angles. The flourishing importance of leadership improvement activities in promoting engagement has been mentioned through practitioners and academics culminating. However, excessive ranges of transformational leadership to the organisation assist no longer simplest to enforce and observe banking procedures (i.e. organizational culture), however additionally growth the future expectancies of employees (i.e. organizational commitment)

Bass and Avolio (1990) found that Individual improvement consists of delegating responsibilities and duties to followers to facilitate the improvement of recent abilities and to offer difficult opportunities. In unique words, the manager is effective and obsessed with the future Bono and Judge, (2004). In terms of hypothesis 3 , effect of the evaluation suggests large relationship among organizational lifestyle and organizational commitment.

According to the findings, there is a positive association between employee engagement and job satisfaction. According to Robinson et al. (2004), employee engagement may be completed through the advent of wholesome organizational environment. Zaini et al. (2009) abstracted that in private and public sector employee's satisfaction of rewards was associated with job satisfaction.

Association between organizational commitment and organizational culture factors are needed for control to replace and review processes and routines in order to change their service offering as needed. Next is the association between employee engagement and job satisfaction. Successful employee engagement encourages banks to improve the efficiency of department employees in order to give novel services. Studies seek out the control of significance on employee engagement via implementing organizational culture and commitment with the transformational leadership.

\section{Conclusion}

Our result display that employee engagement indirectly affected by transformational leadership, which turned substantial clues to the essential to conduit the transformational leadership using organizational culture and customer relations. Transformational leadership is one of the important internal changes through resources and time allocation. Unique manage variables have been taken into consideration to 
recognize the quantity to which gender, age and the duration of carrier can be associated with job satisfaction. With these work factors organisation commitment and organizational culture as mechanisms for enhancing the employee engagement with the aid of using setting new regulations that can lead to new challenges.

\section{References}

Allen, N. J., \& Meyer, J. P. (1990). The measurement and antecedents of affective, continuance and normative commitment to the organization, Journal of Occupational Psychology, 63(1), 1-18. https://doi.org/10.1111/ j.2044- 8325.1990.tb00506.x.

Avolio, B. J., \& Bass, B. M. (1995). Individual consideration viewed at multiple levels of analysis: A multi-level framework for examining the diffusion of transformational leadership, Leadership Quarterly, 6, 199-218. https://dx.doi.org/10.1016/1048-9843 (95)90035-7.

Bagozzi, R. P., \& Yi, Y. (1988). On the evaluation of structural equation models, Journal of the Academy of Marketing Science, 16(1), 74-94. https://doi.org/10.1177/0092070388 01600107.

Bakker W. B. \& Schaufeli, A.B. (2008). Schaufeli Positive organizational behaviour: Engaged employees in flourishing organizations, Journal of Organizational Behaviour, 29, 147-154, doi:10.1002/job.515.

Bass, B. M. (1999). Two decades of research and development in transformational leadership. European journal of work and organizational psychology, 8(1), 9-32.

Bass, B. M., \& Avolio, B. J. (1990). Improving organizational effectiveness through transformational leadership, Thousand Oaks: Sage Publications.

Black, J. S., \& Gregersen, H. B. (1992). When Yankee comes home: Factors related to expatriate and spouse repatriation adjustment, Journal of International Business Studies, 22, 671-694.

Bono, J. E., \& Judge, T. A. (2004). Personality and Transformational and Transactional Leadership: A MetaAnalysis, Journal of Applied Psychology, 89, 901-910. http://dx.doi.org/10.1037/0021-9010.89.5.901.

Brown, S.P. \& Leigh, T.W. (1996). A new look at psychological climate and its relationship to job involvement, effort and performance. Journal of Applied Psychology, 81, 358-368.

Buchingham, C. \& Coffman, M. (1999). Coffman First, break all the rules: What the world's greatest managers do differently, Simon \& Shuster, New York.

Burns, J. M. (1978). Leadership. New York: Harper and Row.

Chalofsky, N., \& Krishna, V. (2009). Meaningfulness, commitment, and engagement: the intersection of a deeper level of intrinsic motivation, Advances in Developing Human Resources, 11, 189-203.

Christian, M. S., Garza, A. S., \& Slaughter, J. E. (2011). Work engagement: A quantitative review and test of its relations with task and contextual performance, Personnel Psycbology, 64(1), 89-136. https://doi.org/10.1111/ j.1744-6570.2010.01203.x.

Danks, N., \& Ray, S. (2018). Predictions from partial Least square models. In F. Ali, S. M. Rasoolimanesh, \& C. Cobanoglu (Eds.), Applying partial Least squares in tourism and hospitality research, Emerald Publishing Limited, 35-52, https://doi.org/10.1108/978-1-78756-699-620181003.

Demerouti, E., Bakker, A.B., Nachreiner, F., \& Schaufeli, W.B. (2001). The Job Demands-resources Model of Burnout, Journal of Applied Psychology, 86, 499-512.

Fornell, C., \& Larcker, D. F. (1981). Evaluating structural equation models with unobservable variables and measurement error, Journal of Marketing Research, 18(1), 39-50. https:// doi.org/10.2307/3151312. 
Linking Transformational Leadership with Employee Engagement through Organizational Commitment...

Gruenfeld, D. H., Mannix, E. A., Williams, K. Y., \& Neale, M. A. 1996. Group composition and decision making: How member familiarity and information distribution affect process and performance, Organizational Behavior and Human Decision Processes, 67, 1-15.

Hair, J. F., Black, W. C., Babin, B. J., \& Anderson, R. E. (2010). Multivariate data analysis (7th ed.). Pearson.

Henseler, J., Dijkstra, T. K., Sarstedt, M., Ringle, C. M., Diamantopoulos, A., \& Straub, D. W. (2014). Common beliefs and reality about PLS, Organizational Research Methods, 17(2), 182-209. https://doi.org/10.1177/ 1094428114526928.

Herzberg, F. (1974). Motivation-hygiene profiles, Organizational Dynamics, 3(2), 18-29.

Howell, J. M., \& Avolio, A. J. (1993). Transformational leadership, transactional leadership, locus of control, and support for innovation: Key predictors of consolidated-business-unit performance, The Journal of Applied Psychology, 78, 891"902.

Kahn, W. A. (1992). Psychological conditions of personal engagement and disengagement at work, Academy of Management Journal, 33(4), 692-724. https://doi.org/10.2307 /256287.

Macey, W., \& Schneider, B. (2008). The meaning of employee engagement. Industrial and Organizational Psychology, 1, 3-30. https://doi.org/10.1111/j.1754-9434. 2007.0002.

Massaro, M., Dumay, J., \& Bagnoli, C. (2015). Where there is a will there is a way: IC, strategic intent, diversification and firm performance, Journal of Intellectual Capital, 16(3), 490-517. https:/ / doi.org/10.1108/JIC-07-20140091.

McColl-Kennedy, J. R., \& Anderson, R. D. (2002). Impact of leadership style and emotions on subordinate performance, The Leadership Quarterly, 13(5), 545"559.

Mowday, R.T., Porter, L.W. \& Steers, R.M. (1982). Employee-Organization Linkages: The Psychology of Commitment, Absenteeism and Turnover, San Diego, CA: Academic Press.

Podsakoff, P. M., MacKenzie, S. B., Lee, J.-Y., \& Podsakoff, N. P. (2003). Common method biases in behavioral research: A critical review of the literature and recommended remedies, Journal of Applied Psychology, 88(5), 879-903. https:// doi.org/10.1037/0021-9010.88.5.879.

Preacher, K. J., \& Hayes, A. F. (2008). Asymptotic and re-sampling strategies for assessing and comparing indirect effects in multiple mediator models. Behavior Research Methods, 40(3), 879-891. https://doi.org/10.3758/ BRM.40.3.879.

Robinson, D., Perryman, S., \& Hayday, S. (2004). The drivers of employee engagement: Institute of Employment Studies Report, London, 408.

Saks, A. (2006). Antecedents and consequences of employee engagement, Journal of Managerial Psychology, 21(7), 600-619. DOI 10.1108/02683940610690169.

Salanova, M., Lorente, L., Chambel, M. J., \& Martínez, I. M. (2011). Linking transformational leadership to nurses' extra-role performance: The mediating role of self-efficacy and work engagement, Journal of Advanced Nursing, 67(10), 2256-2266.

Satorra, A., \& Bentler, E. M. (1988a). Scaling corrections for chi-square statistics in covariance structure analysis, 1-13. American Statistical Association 1988 Proceedings of Business and Economics Sections, Alexandria, VA: American Statistical Association.

Schaufeli, W.B., Bakker, A.B., \& Van Rhenen, W. (2007). How changes in job demands and resources predict burnout, work engagement, and sickness absenteeism, Journal of Organizational Behavior. 30(7), 893 - 917. https://doi.org/10.1002/job.595

Orissa Journal of Commerce, 42(3) (C) 2021 
Vijaya Lakshmi Rakatu, Ashok. Kumar Chandra and Mahesh Kumar Soma

Shmueli, G., Ray, S., \& Velasquez Estrada, J. (2016). The Elephant in the Room: Evaluating the Predictive Performance of PLS Models, Journal of Business Research, 69, 4552-4564. https://doi.org/10.1016/ j.jbusres.2016.03.049

Shmueli, G., Sarstedt, M., Hair, J., Cheah, J.-H., Ting, H., \& Vaithilingam, S. (2019). Predictive model assessment in PLS-SEM: Guidelines for using PLS predict, European Journal of Marketing, 53(11), 2322-2347. https:// doi.org/10.1108/EJM-02-2019-0189.

Sowmya K. R. \& Panchanatham, N. (2011). Factors influencing job satisfaction of banking sector employees in Chennai, Indian Journal of Law and Conflict Resolution, Academic Journals, 3(5), 76-79.

Spector, P. E. (1997). Job satisfaction: Application, assessment, causes, and consequences. Thousand Oaks, CA: Sage Publication Inc.

Sundry, B. (2011). Employee Engagement: A Driver of Organizational Effectiveness, European Journal of Business of Management, 3(8), 53- 60.

Tarique, I., Briscoe, D., \& Schuler, R. (2016). International human resource management: Policies and practices for multinational enterprises, (5th ed.). New York, NY: Routledge.

Tharp, M.B. (2009). Four Organizational Culture Types, Haworth Publication, http:/ faculty.mu.edu.sa/public/ uploads/1360757023.3588organizational\%20cult98.pdf

Yukl, G. (1981). Leadership in organizations. Englewood Cliffs, NJ: Prentice-Hall.

Zaini, A., \& Nilufar, S. A. Syed (2009). The effect of human resource management practices on business performance among private companies in Malaysia, International Journal of Business and management, 4 (6), 6572. 